\title{
SHAPING THE FUTURE WITH EVER-EVOLVING REPRESENTATIONS OF THE PAST
}

Neil Asher Silberman 1

It is my great pleasure to offer a tribute to Professor Pedro Paulo Funari and to attempt place his significant contributions to the intellectual development of global, classical, and Brazilian archaeology into theoretical and historical context. In his tireless and enthusiastic mentoring of generations of graduate students at the University of Campinas, in his own prolific publications, and in his participation and critical evaluation of the ongoing initiatives of the World Archaeological Congress (Funari, 2006), Funari is recognized as an international intellectual leader in the discipline (Zarankin, 2014). Yet his contribution has not merely been to preserve and pass on archaeology's accepted techniques and existing body of knowledge; his achievement has been to constantly expand archaeology's boundaries into social themes and political practices seldom explored. I mention here only a few of his publications in English, without fully encompassing his hundreds of publications in Portuguese. Most notable are his socio-economic analysis of Brazilian archaeological practice (Funari, 2002), the utility of archaeology in documenting the crimes of Latin American dictatorships (Zarankin and Funari, 2008), and the role of archaeological education in the formulation of contemporary Brazilian identity (Funari, 2000). His continuing theoretical interest and activism in the field of human rights in Latin America and his contributions to cultural theory has characterized his work, not only within the academy, but also as an engaged public intellectual.

Yet even in his research on specific archaeological sites and subjects, Funari has consistently pushed conventional disciplinary boundaries outward, focusing on the seemingly inevitable entanglement of present and past. Whether interrogating conflicting interpretations of the ethnic character of the 17th century maroon kingdom of Palmares (homogeneously African or multicultural?) (Funari, 2003); rethinking and reevaluating the semiotic significance of the graffiti of Pompeii and, through it, reassessing the dismissal of popular culture within traditional

\footnotetext{
${ }^{1}$ Associate Professor, University of Massachusetts Amherst, Massachusetts, EUA.

E-mail: neil.silberman@gmail.com
} 
classical studies (Funari, 1993); or examining the disciplines and domination of domestic housing in Buenos Aires since the 18th century (Pedro Paulo A. Funari and Zarankin, 2003), Funari's work and the work of his colleagues and students has not only expanded the scope of the archaeological endeavor - it has led to a serious questioning of its basic epistemology. Indeed the issue of co-creation of shared collective memory through intensive collaboration between scholars and the general public (Funari and Carvalho, 2011) may mark the beginning of a move beyond "Public" or "Community" Archaeology toward an evolving "Public Heritage" that does not privilege a particular methodology over the rest.

It was my great honor to visit UNICAMP on two occasions and to see for myself the extraordinary encouragement that Funari has given to his students toward continuous intellectual self-critique and methodological change. Following in the progressive tradition of Paulo Duarte, after whom the UNICAMP Public Archaeology Lab (LAP) is named (Funari and Carvalho 2012), and in the close integration of environmental studies and research into the archaeological work of the university, Funari has been instrumental in creating a transdisciplinary center in which traditional historiography is being transformed into a hybrid of social science, ecology, and humanities. Indeed, I'm convinced that this is a necessary precondition for sustaining the usefulness of historiographical approaches in the unpredictable world of the Anthropocene. The ongoing debates about the concept of "authenticity" in heritage (Gfeller, 2017); the role of human rights concerns in both archaeology and heritage practice (Silverman and Ruggles, 2007); and indeed the impact of globalization on the social contexts, values, and meanings of cultural heritage sites (Labadi and Long, 2010). We are clearly in a period of profound transition, both in the academy and global society. The question, then, is what is to be done? The answer, I believe, lies in a fundamental reevaluation of the relationship between the academy and civil society - and perhaps even more important, in a temporal reorientation of historiographical narrative.

Regarding the first issue: the academic-public co-creation of archaeological and historical understandings (which, as mentioned above, Funari and Carvalho have begun to explore in the context of Public Archaeology), I am convinced that there is much further to go. The growing influence of Participatory Action Research (PAR), in such diverse fields as public health, education, and community development suggests a way forward in which expert-driven agendas give way to collaboration with communities directly or indirectly impacted by 
scholarly research. This is of particular importance in the realm of archaeology and heritage, where the research is undertaken in specific places. As Setha Low has eloquently pointed out, the process is one of placemaking, and the binary between top-down and bottom-up approaches can be transcended by the adoption of PAR methodologies (Low 2014). In fact, Funari made it possible for my colleague Angela Labrador and me to work with the students of LAP-NEPAM to introduce and experiment with the basic concepts and techniques of Participatory Action Research (Coherit Associates, 2014). The object was to convey both empirical facts and creative expressions in a study of the significance of the university campus. For this experiment, the students served as both "experts" and "community" - with what was perhaps the main pedagogical result being a recognition of how blurred those categories can be.

The second issue which I believe to be central to the transformation of archaeology in its role as public discourse is a basic reorientation of our chronological-temporal perspective. The unidirectional trajectory of "time's arrow" from remote past to lived present has been challenged, for both its teleological reductionism (Landa, 1997) and for its distinctive literary form (White, 1987). I would also add that its political valence as inherent political self-justification - whether of elites or of dissidents and critics - is implicit in its traditional forms (Silberman, 1996). In setting up an ontological boundary between "our" history and "their myth," it creates the basis for continuing conflict between "us" and "them" (Silberman, 2013). In this sense, Bruce Trigger's prescient warning about the inherent political instrumentality of archaeology as being inevitably either nationalist, colonialist, or imperialist (Trigger, 1984), can no longer be ignored. For if a shared and inclusive future is the goal of archaeological research, community archaeology, or participatory action research, the narrative form of historiographical expression must transcend the injustices and blindnesses of the present by explicitly representing that goal in its narrative, so that a vision of an imagined future, counterintuitively but powerfully, precedes a reconstruction of the past (cf. Avanessian and Malik, 2016).

There is a clear connection between these two concerns-of historiographical co-creation and narrative construction-in the crystallization of what could be called "public heritage." Indeed, the very structure of LAP-NEPAM at UNICAMP and the research interests of its faculty and students, ranging from ecological science to popular culture to media studies to cultural resource management to classical epigraphy represents an emerging transdisciplinary practice that simultaneously 
addresses the entanglement of past, present, and the uncertainty of the future. And it is one that does not pretend that given enough funding, enough participants, and enough excavation equipment, the Past in the von Rankean sense of "wie es eigentlich gewesen" - "how it actually was" will be discovered once and for all. It has often occurred to me in my career of writing about the history and politics of archaeology and heritage that evolution of accepted historiographical narratives is only partly due to the accumulation of empirical facts. While the gradual accumulation of empirical evidence is the hallmark of all postEnlightenment scholarship and has been used to justify the authoritative "scientific" nature of historical study, historical evidence is rarely selfexplanatory and has to be interpreted. The context for that interpretation has always been the set of socio-economic concerns of the interpreter in whatever era he or she lives. Facts are unquestionably essential, but they do not tell the whole story, nor do they carry an intrinsic significance. In that sense, historiography should be considered to be public discourse that shapes a society's roadmap to its future rather than objectively documents its past (Silberman, 2013a).

The product of historiography, I would argue, is the process of historiography itself. And that process takes place in a constantly changing present, made even more unpredictable in the dawning of the Anthropocene. Indeed, the excitement of new ecological insights and historical discoveries is derived from their juxtaposition with everchanging changing socio-economic conditions and unexpected environmental challenges. True inclusiveness and public engagement can never be achieved if historiographical authority remains exclusively in the hands of scholars and officials. As public discourse, history, archaeology, and heritage offer an opportunity for the future to remain open to alternative trajectories, not merely explain why the present disposition of socio-economic power and environmental conditions were historically inevitable.

Conditions have dramatically changed since my last visit to Brazil in 2014. And throughout the world, the relentless progress of climate change and the ascendance of xenophobic neonationalism and religious fundamentalism offer a new context in which the past must be seen. It is high time that the intimate interaction between understandings of the past and anticipations of the future be recognized and incorporated into the historiographical process. Whether archaeological, literary, or performative, history is what history does in the era in which we live. And the doing an ongoing social obligation for the academy and the general public alike. We are on the verge of a Copernican reorientation in 
historical reflection, in which the future, not the past, is the center of our chronological universe. The ethical imperative is to recognize that there are no final answers to historical questions. The crucial responsibility of all the historiographical disciplines-very much in line with the encouragement that Funari has given his students - is that historical and archaeological research is and should always be an ongoing process of social and political debate and reflection-with all its awesome consequences for the recognition of human rights, toleration of cultural coexistence, and enhancement of human dignity.

\section{References}

AVANESSIAN, Armen, e MALIK, Suhail. The Speculative Time Complex. In The Time Complex. Post-Contemporary, 2016, 5-56. Miami, Florida: [NAME] Publishers.

Coherit Associates. "Values-Based Heritage Approaches for Sustainable Development." 2014. http://coherit.com/projects.html.

FUNARI, Pedro Paulo Abreu. Graphic Caricature and the Ethos of Ordinary People at Pompeii. Journal of European Archaeology 1 (2): 1993, 133-50. 2000, 182-85.

Archaeology, Education and Brazilian Identity. Antiquity 74 (283):

. Class Interests in Brazilian Archaeology. International Journal of Historical Archaeology 6 (3): 2002, 209-16.

Conflict and the Interpretation of Palmares, a Brazilian Runaway Polity. Historical Archaeology 37 (3): 2003, 81-92.

. The World Archaeological Congress from a Critical and Personal Perspective. Archaeologies, 2006, no. 1:73.

FUNARI, Pedro Paulo, CARVALHO,Aline Vieira. Inclusion in Public Archeology in Brazil: Remarks on Collaborative Practices. Archaeologies 7 (3): 2011, 554-73.

. Universidades, Arqueologia e Paulo Duarte. Revista do Museu de Arqueologia e Etnologia 0 (22): 2012, 89-96. 
FUNARI, Pedro Paulo A., ZARANKIN., Andrés. Social Archaeology of Housing from a Latin American Perspective: A Case Study. Journal of Social Archaeology 3 (1): 2003, 23-45.

GFELLER, Aurélie Élisa. The Authenticity of Heritage: Global NormMaking at the Crossroads of Cultures. The American Historical Review 122 (3): 2017, 758-791.

LABADI, Sophia, LONG, Colin. Heritage and Globalisation. Milton Park, Abingdon, Oxon, England; New York, NY: Routledge, 2010.

LANDA, Manuel De. A Thousand Years of Nonlinear History. First Edition edition. New York: Zone Books, 1997.

LOW, Setha M. Spatializing Culture: An Engaged Anthropological Approach to Space and Place. In The People, Place and Space Reader, 2014.

SILBERMAN, Neil A. Promised Lands and Chosen Peoples: The Politics and Poetics of Archaeological Narrative. In Nationalism, politics, and the Practice of Archaeology.Cambridge University Press, 1996.

Heritage Interpretation as Public Discourse. In Understanding Heritage. Ed. Albert, Marie-Theres / Bernecker, Roland / Rudolff, Britta, 21-33, 2013a. Berlin: De Gruyter.

. The Tyranny of Narrative: History, Heritage, and Hatred in the Modern Middle East. Journal of Eastern Mediterranean Archaeology and Heritage Studies 1 (2): 2013b, 175-184.

SILVERMAN, Helaine, e D. Fairchild RUGGLES. Cultural Heritage and Human Rights. New York; London: Springer, 2007.

TRIGGER, Bruce G. Alternative Archaeologies: Nationalist, Colonialist, Imperialist. Man 19 (3): 1984, 355-70.

WHITE, Hayden. 1987. The Content of the Form: Narrative Discourse and Historical Representation. Baltimore: The Johns Hopkins University Press.

ZARANKIN, Andrés. FUNARI, Pedro Paulo A. (Historical Archaeology). In Encyclopedia of Global Archaeology, edited by Claire Smith, 2937-39, 2014. New York, NY: Springer New York.

ZARANKIN, Andrés, FUNARI, Pedro Paulo Abreu. Eternal Sunshine of the Spotless Mind': Archaeology and Construction of Memory of Military Repression in South America (1960-1980)." Archaeologies 4 (2): 2008. 31027. 